\title{
Mises en scène et mémoires de la consécration d'église au Moyen Âge.
}

Centre d'études médiévalesd'Auxerre, Table ronde des 27-29 juin 2005

\section{Didier Méhu}

\section{(2) OpenEdition}

\section{Journals}

Édition électronique

URL : https://journals.openedition.org/cem/976

DOI : $10.4000 /$ cem. 976

ISSN : 1954-3093

Éditeur

Centre d'études médiévales Saint-Germain d'Auxerre

Édition imprimée

Date de publication : 15 août 2004

ISSN : 1623-5770

Référence électronique

Didier Méhu, « Mises en scène et mémoires de la consécration d'église au Moyen Âge. », Bulletin du centre d'études médiévales d'Auxerre | BUCEMA [En ligne], 8 | 2004, mis en ligne le 07 février 2007, consulté le 22 septembre 2022. URL : http://journals.openedition.org/cem/976 ; DOI : https://doi.org/ 10.4000/cem.976

Ce document a été généré automatiquement le 22 septembre 2022.

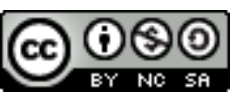

Creative Commons - Attribution - Pas d'Utilisation Commerciale - Partage dans les Mêmes Conditions 4.0 International - CC BY-NC-SA 4.0

https://creativecommons.org/licenses/by-nc-sa/4.0/ 


\title{
Mises en scène et mémoires de la consécration d'église au Moyen Âge.
}

Centre d'études médiévalesd'Auxerre, Table ronde des 27-29 juin 2005

\author{
Didier Méhu
}

1 Au Moyen Âge central, le sacré est avant tout ce qui a été consacré, et l'on compte dans cette catégorie les autels, les églises, certains objets utilisés pour le culte, et les cimetières à partir de la fin du $\mathrm{X}^{\mathrm{e}}$ siècle. Les lieux et les objets consacrés constituent des pôles à partir desquels se pense une renovatio ecclésiale qui est, en ces temps de symbiose ecclesia. societas, une régénération sociale. Aussi, la cérémonie de consécration, dont le rituel se précise à mesure des codifications liturgiques qui accompagnent la période carolingienne, apparait-elle comme l'acte fondateur d'un nouvel espace-temps. Le rituel liturgique s'efforce de le mettre en scène ; les paroles prononcées, les gestes effectués et les mesures prises pour en conserver le souvenir contribuent à inscrire l'événement dans la mémoire sociale de la communauté.

2 Comme le soulignent les sermons de consécration dès l'Antiquité tardive, avant même que le rite soit soigneusement détaillé dans les ordines, la consécration opère une transformation semblable à celle du baptême. Le sermon qui clôt la cérémonie est l'occasion de fonder la fête de la dédicace, pierre angulaire du nouveau calendrier pour les voisins du sanctuaire. Au XI ${ }^{\mathrm{e}}$ siècle, la narration de la dédicace devient un genre littéraire qui valorise le locus consacré, fait l'éloge de ses bâtiments et souligne la générosité de ses bienfaiteurs. Insérées dans les cartulaires ou rappelées dans les privilèges pontificaux, ces narrations s'articulent aux inscriptions lapidaires gravées sur les murs des églises et aux images peintes qui rappellent l'événement, ses gestes et ses rituels.

3 La table ronde s'inscrit dans le prolongement des recherches sur les objets, les lieux et les territoires sacrés dans l'Occident médiéval qui ont fait l'objet d'une première rencontre à Nice en janvier 2004, organisée par Michel Lauwers. Ce second volet envisage une réflexion croisée (historiens, historiens de l'art, musicologues, archéologues) sur les modes de mises en scène et de commémoration des lieux, de 
l'espace et du temps consacrés. Pour plus de cohérence, nous nous concentrerons sur l'Occident, de l'Antiquité tardive au Moyen Âge central.

4 La table ronde envisage trois thèmes :

- Les rituels de la consécration : les ordines de la consécration, les circuitus autour du lieu consacré (ou à consacrer), les translations de reliques et le scellement de reliques dans les autels...;

- Les "performances" de la consécration : les chants liturgiques et la musique, les odeurs, les gestes, les paroles (notamment les sermons de consécration ou les allocutions lors de conciles liés à une consécration) ;

- Les mémoires de la consécration : les images de dédicace, les inscriptions lapidaires, les souvenirs littéraires (narrations de la dédicace), les souvenirs “juridiques” (privilèges), les pèlerinages...

\section{Participants pressentis :}

- Nicole Bériou, Université Lyon II

- Alexis ChARANSONNET, Université Lyon II

- Martine clouzot, Université de Bourgogne

- Marie-Noëlle COLETTE, EPHE

- Kathleen cusHing, Keele University

- Jennifer HARRIS, Toronto University, Saint Michael College

- Dominique IOGNA-PRAT, CNRS, Dijon/Auxerre

- Michel LAUWERs, Université de Nice

- Robert MARCouX, Université Laval, Québec. Université de Bourgogne

- Didier MÉnu, Université Laval, Québec

- Éric palazzo, Université de Poitiers

- Agostino PaRAvicini Bagliani, Université de Lausanne

- Susan RANKIN, Cambridge University, Emmanuel College

• Hedwig RöCKELEIN, Universität Göttingen

- Daniel Russo, Université de Bourgogne

- Cécile TREFFoRT, Université de Poitiers

- Jean WIRTH, Université de Genève 